\title{
The Comparison of the Evolution of the Standard Yi in the Northern Dialect and the Yi Script in the Yi Script "Nadokuse"
}

\author{
Renqin Yang \\ College of Yi Studies, Southwest Minzu University, Chengdu, China \\ Email:812831372@qq.com
}

How to cite this paper: Yang, R.Q. (2020) The Comparison of the Evolution of the Standard Yi in the Northern Dialect and the Yi Script in the Yi Script "Nadokuse". Open Access Library Journal, 7: e6706. https://doi.org/10.4236/oalib.1106706

Received: August 11, 2020

Accepted: August 24, 2020

Published: August 27, 2020

Copyright $\odot 2020$ by author(s) and Open Access Library Inc.

This work is licensed under the Creative Commons Attribution International License (CC BY 4.0).

http://creativecommons.org/licenses/by/4.0/

\section{(c) (i) Open Access}

\begin{abstract}
Paul Vial, the author of "Nadokuse", used a variety of different materials to reflect the social history and traditional culture of the Sani people from the end of the 19th century to the beginning of the 20th century. This book is a very precious historical document for the Shilin Sani people. The entire book is written in ancient Yi language. The author compares the ancient Yi language with the modern standard Yi language, analyzes the process and results of its evolution, and finds out the similarities and differences between the ancient Yi language and the standard Yi language.
\end{abstract}

\section{Subject Areas}

Linguistics

\section{Keywords}

Nadokuse, Yi Language, Comparison

\section{Introduction to "Nadokuse" and Author}

In 1876, Paul Vial entered the seminary of the Paris Foreign Mission, and after three years of study, he was appointed as a priest and sent to Yunnan province, China. In 1880, Paul Vial first went to Yanjin in Zhaotong to learn Chinese and local culture, and then went to Yangbi in Dali to preach for five years. From 1885 to 1886, he managed a small diocese in Songming, not far from Kunming [1]. Just after the Sino-French War, the hostility of the local Han people towards the French was so widespread that Paul Vial "decided to go to a new place to 
find a new believer in Jesus Christ". In 1886, he arrived in Lunan State. It was the first time he saw the "Luoluo" at the street. He met a few Sani people of Yi ethnic group in Shilin by chance. After some exchanges, I became interested in the Sani people. Then he settled in Tiansheng Village, Shilin County and named himself "Deng Mingde". The people called him: "Catholic father Deng". Soon he moved to Lu Meiyi Village to spread Catholicism to Sani Yi District, successively established churches and schools, set up clinics, built water conservancy projects, and spread Yi culture to Western countries. He was one of the first outstanding missionaries to spread Yi culture.

"Nadokuse" is translated based on part of the contents of the "Bible". The author also added many Sani people's history, culture, living habits, customs and religions, etc., a question-and-answer book written in Yi language, called Yicharacter "Bible" [2]. The Luoluo language "Nadoku" means "question and answer", and "Se" means "book". This Yi language "Bible" mainly describes a French missionary who came to Yunnan at the end of the 19th century and the beginning of the 20th century. He had a missionary career in Yunnan for more than 30 years [3] (Research on Ancient Books in Southwest China). The document is recorded as an important reference material for the study of the Yi people in Yunnan. It is also a documentary material for future generations to understand the early Yi people's history, language, culture, religious rituals, and customs [4]. In this book, Paul Vial vividly described how he used his experience to spread the gospel among them after he met the Luoluo people.

Paul Vial, the author of "Nadokuse", invited Bimo $\left(\mathrm{pi}^{33} \mathrm{mo}^{33}\right)$, a well-known local Yi ethnic group, to discuss and write it in the ancient Yi language. The whole book seems to be a translation of Catholic teachings from French into ancient Yi language, and it is aimed at the time [1]. The religious customs of the Sani people are regulated by the Catholic canon and the Catholic doctrine is simply explained in the Sani language that people use, which makes people feel simple, clear and intimacy. This book reflects the social history and traditional culture of the Sani people from a variety of perspectives and with a variety of materials. Due to the obstruction of the living environment, extremely inconvenient transportation, lagging economic and cultural development, and backward education and technology, the Sani people did not produce scholars who studied their culture for a long period of time, and other scholars wrote about Sani's historical and cultural materials. Cultural materials lack and there has no in-depth understanding, so this book is a very precious historical document for Shilin people. The content of the Yi biblical "Nadokuse" is rich and diverse [1]. It not only contains knowledge of Catholicism, but also includes the astronomy and geography of the Yi people, customs, and religious culture of the Yi people. This Yi scripture is roughly divided into seven parts: The origin of heaven and earth, the rules of Jesus, the general holy religion, the four canons of the holy religion, the signs of grace, the prayer, and the person who prays. This book is mainly written in the form of question and answer, which is easy to understand. 


\section{Comparison between Sani Luoluo and Liangshan Shengzha}

Every language is composed of monosyllable words at the beginning of its birth. Then with the development of the times and the progress of society, the language is constantly changing over time [2]. In Shilin, due to the geographical location, Sani luoluo language has many dialects, and each dialect speaks differently, with changes in consonants, vowels, and tones. There is only one basic dialect in Sani luoluo, and all dialects can be summarized as Wuyu and Ayu. Generally speaking, ou or a is used as a sign to distinguish Wuyu and Ayu, such as: sou sa (understand), dzou dza (eating), tsou tsa (salt), rou re (kind), etc. The Wuyu language is spoken by the northern tribes, while the southern tribes speak Ayu, while the Shilin Sani dialect belongs to Ayu. The tribes are not distinguished by language, because several tribes speak the same dialect. Therefore, the same tribe changes with the terrain and east-west, resulting in different dialects.

In Luoluo language, almost all consist of one consonant and one vowel, such as a $\mathrm{o}$ i ba de to va, etc. The longest word has two consonants, such as tlo tla hlo hluo. There is no nasalization phenomenon in Luoluo language. Due to the limited vocabulary of Luoluo language, many words are borrowed from Chinese in daily life, so some changes in pronunciation may occur.

In the standard Yi language of the northern dialect, there is no compound consonant phenomenon, and there is no phenomenon that consonants form syllables by themselves. The Luoluo language has these two phenomena. In terms of tones, Liangshan Yi language has 4 tones $55,44,33$, and 21 , while Luoluo language has only 3 tones 55, 33, 21. From the tones, we can see that Luoluo language has no sub-high tone. 44 tones are not found in Yi Nuo dialect in Liangshan Yi dialect. But the falling tone of Yinuo Tu language is higher than that of $21[5]$.

\section{The Similarities and Differences between Sani Luoluo Character Ancient Yi Language and the Northern Dialect Standard Yi Language}

There are a total of 7 parts in "Nadokuse". The Sani Luoluo script has many similarities and differences with the standard Yi script of the northern dialect [2]. The similarities and differences are summarized as follows: all have consonants, vowels, and tones. Some characters have not changed since ancient times. For example, ma ${ }^{33}$, which means the quantifier " $\mathrm{a}$ " in Luoluo, and the quantifier in the standard Yi script of the northern dialect, has not changed in its shape, syllable, and tone meaning less. Many characters have to change, either in tone, in shape, or in syllables. There are many consonants in Sani Luoluo text that form syllables. There are many phenomena of multiple sounds in a word. For example, a word may have multiple syllables when the meaning and composition of the sentence are different. There are 3 tones in the Luoluo text, and there 
may be one. A word has 3 tones, or a word has multiple syllables and multiple meanings. The word $\quad \mathrm{la}^{33}$ has been developed to this day, and the meaning of the font has not changed, but the syllable has changed. Luoluo character is pronounced $\quad \mathrm{li}^{33}$, while the standard Yi language is $\mathrm{la}^{33}$.

Through comparison, it is found that the vowel changes loose vowel i-tight vowel a. There are many changes in similar vowel sounds, and many changes in consonants. In Luoluo text, the negative word “田” $\mathrm{ma}^{21}$ means “no", and in Liangshan ancient Yi text, the word " " $\mathrm{ma}^{21}$ also means "no". Comparing these two words, the pronunciation has not changed. It hasn't changed, but the font has evolved from the ancient Luoluo script to the standard Yi script, with certain changes. Liangshan ancient Yi script is similar to it. It can be seen from the "Nadokuse" that the Sani luoluo people also worship their ancestors, and they also value the soul. The soul says $i^{55} \mathrm{a}^{33}$ in the luoluo text, but in Liangshan it is pronounced $z 2_{-1}^{33} \mathrm{a}^{33}$, the font is very similar, the standard Yi text has some variations in the ancient Luoluo text, but the font is roughly the same. It can also be seen that the "birth" $\mathrm{o}^{33}$ in the ancient Luoluo script is pronounced $\mathrm{u}_{-}{ }^{33}$ in the standard Yi language. The Yi script in the ancient Luoluo script is very similar to the standard Yi script, with only a small part changed. In the ancient Luoluo script, $\mathrm{l}^{21}$, while in the standard Yi language $\mathrm{li}^{21}$, the word is the same, but the vowels have changed. The numerals one, two and three in the ancient Luoluo script are similar to those in the standard Yi script, and the syllables have changed. However, the standard Yi script evolved slowly from the ancient Yi script, so the foundation of the Yi script is very similar. In the ancient Luoluo script, "do" is also pronounced $\mathrm{mu}^{33}$, while the northern dialect Yi language is also pronounced $\mathrm{mu}^{33}$, the pronunciation is the same, and the glyph is slightly changed in the ancient Yi script. In Sani Luoluo, consonants form syllables on their own. It is common for a word to have multiple tones. Sometimes a word can contain 3 tones. A word has multiple syllables, and its pronunciation is determined according to the semantics of the sentence and phrase, or it is pronounced according to the sound change phenomenon of a fixed phrase.

The table of similarities and differences is as follows:

\begin{tabular}{|c|c|c|c|c|}
\hline $\begin{array}{l}\text { Luoluo } \\
\text { script }\end{array}$ & $\begin{array}{l}\text { Standard } \\
\text { Yi script }\end{array}$ & Meaning & Similar & Different \\
\hline “田” $\mathrm{ma}^{21}$ & “ " $\mathrm{ma}^{21}$ & no & Pronunciation meaning & font \\
\hline$i^{55} a^{33}$ & $z_{0}^{23} a^{33}$ & soul & $\begin{array}{l}\text { Font (very similar) } \\
\text { Second pronunciation }\end{array}$ & $\begin{array}{c}\text { First vowel and tone } \\
\text { pronunciation }\end{array}$ \\
\hline $\mathrm{o}^{33}$ & $\mathrm{u}_{-}{ }^{33}$ & birth & $\begin{array}{l}\text { Font (very similar) } \\
\text { Consonant tone }\end{array}$ & vowel \\
\hline $1^{21}$ & $\operatorname{li}^{21}$ & & font & Vowel pronunciation \\
\hline $\mathrm{li}^{33}$ & $1 a^{33}$ & come & Font Consonant tone & Vowel pronunciation \\
\hline $\mathrm{mu}^{33}$ & $\mathrm{mu}^{33}$ & do & Pronunciation meaning & font \\
\hline
\end{tabular}


In short, Sani Luoluo script and Liangshan standard Yi script have many similarities. Liangshan standard Yi script evolved from ancient Yi script, so many glyphs have similar pronunciations. In Liangshan Yi language, overlapping words are represented by , and in Sani luoluo language, they are all the same in shape. There is also $\mathrm{mu}^{33} \mathrm{sky} \mathrm{s} \mathrm{s}^{33}$ god $\mathrm{pa}^{21}$ father $\mathrm{do}^{21}$ words $\mathrm{na}^{33}$ listen, the whole sentence means to listen to the words of the priest (God). "Father" is still pronounced $\mathrm{pa}^{55}$ in the standard Yi language of the northern dialect. The tone changes from falling tone 21 to high flat tone 55, and the meaning of the word and the consonant vowels remain unchanged. "Word" is also said to be $\mathrm{do}^{21}$ in the standard Yi language, with changes in the shape of the characters, and the meaning and pronunciation of the tones. Due to the development and progress of society and the rapid advancement of urbanization, the living environment of the Sani people continues to be integrated with many other ethnic groups, the contact of various languages, and the language environment has changed, which has caused the traditional Yi language to undergo earth-shaking changes.

\section{Conclusion}

Paul Vial was an early foreign missionary who studied the Yi people's cultural knowledge comprehensively. His research areas include Yi people's religion, history, customs, literature, folk tales, language, writing, and clothing. He also tried to explore issues such as the origin of the Yi nationality. His research has been affirmed by many Yi scholars and laid a solid foundation for the study of Yi cultural knowledge. From "Nadokuse", we can find that some Yi characters are similar to the standard Yi characters in the northern dialect, and the standard Yi characters evolved from the ancient Yi characters. The ancient Yi people have many ethnic customs and cultures that are similar, just as many teachers say the older more and more similar they are. Indeed, after reading Paul Vial's book, I found that Yunnan Sani and the northern dialect of Yi language have many similarities, including words, grammar, pronunciation, etc. There are many areas for research in the linguistics major, but the author lacks professional knowledge, and I still need to read a lot of relevant professional knowledge, and then I will study the Yi script in depth.

\section{Conflicts of Interest}

The author declares no conflicts of interest regarding the publication of this paper.

\section{References}

[1] Huang, J.M. and Yan, H.S. (2003) The Yi People in Yunnan in the Collection of Paul Vial's One Hundred Years Ago. Yunnan Education Press, Kunming.

[2] Li, P. (2015) Research on the Yi Script "Nadokuse". Central University for Nationalities, Beijing.

[3] Zeng, L.M. (2018) French Missionary Paul Vial and the Society of the Han-Yi 
Community. Research on Ancient Books in Southwest China.

[4] Ji, C.Z. (2019) Paul Vial's Missionary Activities in Yi District of Yunnan Province in Yi People in Yunnan a Century Ago. Journal of Honghe University, 17, 42-46.

[5] Chen, S.L., Bian, S.M. and Li, X.Q. (1985) A Brief History of Yi Language. National Publishing House, Beijing. 